\title{
Conversion from Epoetin Alfa to Darbepoetin Alfa: Effects on Patients' Hemoglobin and Costs to Canadian Dialysis Centres
}

\author{
Jessica Jordan, Joanne Breckles, Valerie Leung, Maryann Hopkins, and Marisa Battistella
}

\begin{abstract}
Background: The erythropoiesis-stimulating agents epoetin alfa (EPO) and darbepoetin alfa (DPO) effectively treat the anemia that occurs in most patients undergoing hemodialysis. Published studies indicate that these 2 agents have similar efficacy and safety outcomes, but their relative costs in actual practice in Canada have not been extensively studied.

Objectives: To determine the relative utilization and cost of erythropoiesis-stimulating agents in Canadian practice. Secondary objectives were to examine various clinical parameters in patients receiving these drugs.
\end{abstract}

Methods: In this retrospective, open-label, observational study, 3 hospital-based hemodialysis centres in Ontario, Canada, converted patients from EPO to DPO over the period July 2004 to April 2006. The starting dose-conversion ratio was 200:1. The dose of DPO was changed, as needed, to achieve the same target hemoglobin $(\mathrm{Hb})$ as before the conversion (110-120 g/L). For 3 to 6 months before conversion, and for 6 to 12 months after, weekly dose of erythropoiesis-stimulating agent, dose-conversion ratio, serum $\mathrm{Hb}$, ferritin, and transferrin saturation were recorded for each patient at all 3 sites. One site also documented medication administration errors before and after the conversion.

Results: Data were collected for a total of 442 patients. Baseline patient characteristics were similar across the 3 sites. The median dose-conversion ratio for each hemodialysis centre ranged from 288:1 to 400:1, and the average annual per-patient savings varied between $\$ 2140$ and $\$ 4711$. No clinically meaningful differences between EPO and DPO were reported in terms of patients' serum hemoglobin levels, iron dose, or number of transfusions. With DPO, the relative risk of medication administration errors was reduced by $72 \%(p<0.001)$ (based on data from one site).

Conclusion: In this real-world evaluation of the clinical effectiveness and cost-efficiency of switching patients from EPO to DPO, patients' clinical outcomes were maintained while considerable reductions in cost were achieved.

Key words: epoetin alfa, darbepoetin alfa, dose conversion, cost saving, economic analysis

\section{RÉSUMÉ}

Contexte : Les agents stimulant l'érythropoïèse, l'époétine alfa (EPO) et la darbépoétine alfa (DPO), traitent efficacement l'anémie qui survient chez les patients hémodialysés. Des études publiées montrent que l'innocuité et l'efficacité de ces deux agents sont similaires, mais leurs coûts relatifs dans la pratique actuelle au Canada n'ont pas été étudiés de façon exhaustive.

Objectif : Déterminer l'utilisation et le coût relatifs des agents stimulant l'érythropoïèse dans la pratique au Canada. Les objectifs secondaires étaient d'examiner divers paramètres cliniques chez les patients recevant ces médicaments.

Méthodes : Dans le cadre de cette étude observationnelle, ouverte rétrospective, trois services hospitaliers d'hémodialyse en Ontario, au Canada, ont fait passer les patients de l'EPO à la DPO pendant la période allant de juillet 2004 à avril 2006. Le facteur de conversion de la dose de départ était de $200: 1$. Les doses de DPO ont été modifiées, au besoin, pour atteindre les mêmes taux cibles d'hémoglobine $(\mathrm{Hb})$ qu'avant la conversion (de 110 à $120 \mathrm{~g} / \mathrm{L}$ ). De 3 à 6 mois avant la conversion, et pendant une période de 6 à 12 mois par la suite, on a noté la dose hebdomadaire d'agent stimulant l'érythropoï̀se, le facteur de conversion de la dose de maintien, le taux d'Hb sérique, le taux de ferritine et le taux de saturation de la transferrine pour chaque patient dans les trois services. Un service a aussi consigné les erreurs d'administration des médicaments avant et après la conversion.

Résultats : Les données ont été recueillies chez un total de 442 patients. Les caractéristiques de base des patients étaient similaires dans les trois services. Le facteur de conversion médian de la dose de maintien pour chaque service d'hémodialyse variait de 288: 1 à $400: 1$ et les économies annuelles moyennes par patient variaient de 2140 \$ à 4711 \$. Aucune différence cliniquement significative entre l'EPO et la DPO n'a été observée pour ce qui est des taux d'Hb sérique, de la dose de fer ou du nombre de transfusions. Le risque relatif d'erreurs dans l'administration des médicaments a été réduit de $72 \%(p<0,001)$ avec la DPO (selon les données provenant d'un service).

Conclusion : Cette évaluation en contexte réel de l'efficacité clinique et de la rentabilité du remplacement de l'EPO par la DPO a révélé que les résultats cliniques ont été maintenus tout en permettant des réductions de coût considérables.

Mots clés : époétine alfa, darbépoétine alfa, conversion de dose, économie de coût, analyse économique

[Traduction par l'éditeur] 


\section{INTRODUCTION}

Tn patients with chronic kidney disease, the kidneys are unable to produce enough erythropoietin to stimulate adequate production of red blood cells. Low red blood cell production results in anemia, reduced oxygen transport, chronic fatigue, and heart disease. ${ }^{1}$ Although correction of anemia in chronic kidney disease has not been directly shown to improve cardiac outcomes, anemia is associated with the development and worsening of cardiovascular disorders. ${ }^{2}$ In addition, some studies have shown that correction of anemia may improve quality of life for patients with renal disease. ${ }^{3,4}$

The Canadian Society of Nephrology recommends the administration of erythropoiesis-stimulating agents, such as epoetin alfa (EPO) and darbepoetin alfa (DPO), to treat anemia. The Society's clinical practice guideline states that for patients with chronic kidney disease, treatment with an erythropoiesis-stimulating agent should begin when iron stores have been corrected, other reversible causes of anemia have been treated, and the patient has a sustained hemoglobin $(\mathrm{Hb})$ level below $100 \mathrm{~g} / \mathrm{L}$.

Erythropoiesis-stimulating agents are manufactured through recombinant DNA technology and are administered by subcutaneous (SC) or intravenous (IV) injection. EPO is approved in Canada for 1 to 3 times weekly dosing, ${ }^{6}$ whereas DPO is administered once weekly or once every 2 weeks. ${ }^{7}$ In general, the Canadian Society of Nephrology recommends that an erythropoiesis-stimulating agent be administered by the SC route for patients who are not undergoing dialysis and those undergoing peritoneal dialysis and by either the IV or SC route (according to individual patient need and preference) for those undergoing hemodialysis. The recommended dose and administration schedules for EPO and DPO differ, and many chronic kidney disease and dialysis programs have decided to convert patients from EPO to DPO therapy to extend dosage intervals and potentially reduce the cost of anemia treatment.

For conversion from EPO to DPO, a fixed conversion ratio of $200 \mathrm{IU}$ EPO to $1 \mu \mathrm{g}$ DPO was suggested by the manufacturer. ${ }^{7}$ With this ratio, the peptide masses of the agents are equivalent. However, later studies have indicated that the linear relationship between baseline EPO dose and maintenance DPO dose becomes curvilinear at EPO doses greater than 7000 units/week: at higher doses, less DPO is required than a 200:1 conversion ratio would predict. ${ }^{7}$ Nonetheless, a recent metaanalysis of 9 studies $^{8}$ reported a reduction in total dose required when patients were converted from $\mathrm{EPO}$ to $\mathrm{DPO}$ according to a starting dose-conversion ratio of 200:1.

Several studies have suggested that patients undergoing hemodialysis can be readily switched from one erythropoiesisstimulating agent to another, but the health outcomes for patients and the effects on cost have not been extensively studied in Canadian clinical practice. In 2005, Shalansky and Jastrzebski9 published an 18-month open-label observational study of 95 patients switched from SC EPO to IV DPO at the Vancouver General Hospital. With the date of the switch to DPO defined as baseline, data were collected retrospectively for 6 months and prospectively for 12 months. The first 6 months of DPO therapy was considered a dose-titration phase. The data were analyzed by comparing 2 periods: the 6 months preceding baseline (EPO phase) and from 6 to 12 months after baseline (DPO phase). Each patient's dose was titrated to a target $\mathrm{Hb}$ of $120-135 \mathrm{~g} / \mathrm{L}$. There was no significant difference in the primary end point ( $\mathrm{Hb}$ level) between the 2 phases. The median DPO dose remained stable throughout the analysis period (6-12 months after baseline), at $30 \mu \mathrm{g} /$ week, whereas the median dose of EPO rose from $8000 \mathrm{U} /$ week at 6 months before baseline to $9000 \mathrm{U} /$ week at baseline. The median 12month cost saving associated with DPO (a secondary outcome) was estimated at $\$ 2200$ per patient. The authors concluded that DPO was able to maintain serum $\mathrm{Hb}$ levels similar to those achieved with EPO at a substantially lower cost.

In another study, published in 2008, Raymond and others $^{10}$ evaluated the dose-conversion ratio between EPO and DPO for patients with anemia of chronic kidney disease in a large provincial renal program in Manitoba. This retrospective analysis included patients with chronic kidney disease who were undergoing hemodialysis or peritoneal dialysis, as well as patients in the pre-dialysis phase. A total of 857 patients who received DPO were compared with 746 patients who had received EPO in previous years. For all 3 patient populations, the dose-conversion ratio between $\mathrm{EPO}$ and $\mathrm{DPO}$ was greater than 200:1. Although the authors did not report drug costs, they stated that the dose-conversion ratios supported the significant cost savings that had been realized by the provincial renal program by switching from EPO to DPO.

The purpose of the study reported here was to further quantify and compare the relative utilization and cost of $\mathrm{EPO}$ and DPO in 3 Canadian hemodialysis centres. Secondary objectives in this study were patients' clinical outcomes $(\mathrm{Hb}$, ferritin, transferrin saturation, number of transfusions) and the frequency of medication errors (at one centre).

\section{METHODS}

\section{Study Design}

Three hospital-based hemodialysis treatment centres in Ontario participated in this retrospective, open-label, observational study. At each of the 3 sites, patients requiring hemodialysis who were treated with EPO and DPO were enrolled. At sites $\mathrm{A}$ and $\mathrm{B}$, patients were included only if they had been treated with $\mathrm{EPO}$ and DPO for the duration of the respective study periods (i.e., before and after conversion from EPO to 
DPO). At site C, any patients who received EPO during the pre-conversion therapy and any who received DPO in the post-conversion period were included. To ensure that results would reflect actual clinical practice, no other inclusion or exclusion criteria were applied. Data for the current analysis were collected retrospectively from medical records at the 3 sites for patients who underwent conversion from EPO to DPO between July 2004 and April 2006.

At each study site, patients undergoing hemodialysis were converted from IV EPO to IV DPO according to the recommended dose-conversion ratio of $200 \mathrm{IU}$ EPO to $1 \mu \mathrm{g}$ DPO, with weekly or every-other-week dosing according to clinical judgment. The starting dose-conversion ratio of 200:1 was chosen on the basis of the equivalent peptide mass of each agent. At one study site (site A), a curvilinear dose-conversion algorithm was used, whereby patients being treated with a higher dose of EPO received DPO according to a higher conversion ratio (from 220:1 to 260:1), as outlined in Table 1 .

For each patient, the dose of erythropoiesis-stimulating agent was titrated to target $\mathrm{Hb}$ according to standard practice at each hemodialysis centre at the time of the study (July 2004 to April 2006) (i.e., $110-120 \mathrm{~g} / \mathrm{L}$ at sites $\mathrm{A}$ and C; $110-130$ $\mathrm{g} / \mathrm{L}$ at site B). Oral iron or IV iron sucrose was administered to maintain transferrin saturation within $20 \%-50 \%$ and serum ferritin between 100 and $800 \mu \mathrm{g} / \mathrm{L}$, as per usual practice at each hemodialysis centre at the time of the study.

\section{Data Collection}

The study duration and frequency of data collection varied slightly across the 3 sites, according to the clinics' individual preferences, to ensure they had sufficient data for their own assessments of the impact of the switch. At both site $\mathrm{A}$ and site $\mathrm{B}$, the pre-conversion period was defined as the 6 months before switching from EPO to DPO, and the postconversion period lasted 9 and 6 months, respectively. At site $\mathrm{C}$, the pre-conversion period lasted 3 months and the postconversion period 12 months. The dose administered was recorded weekly at all 3 sites. At sites A and C, serum $\mathrm{Hb}$ was measured monthly, and ferritin and transferrin saturation were recorded every 3 months. At site $\mathrm{B}, \mathrm{Hb}$ and mean corpuscular volume were recorded twice monthly over the entire study period, whereas transferrin saturation and ferritin were recorded every 2 months.

\section{Medication Administration Errors}

At site A, medication administration errors were recorded weekly on paper medication administration records (MARs) during the 6-month pre-conversion and 9-month post-conversion periods. It was assumed that an omission error had occurred when no dose was documented on either the MAR or the dialysis treatment record. An incorrect-dose error was recorded if the dose or strength was incorrect, or if an extra dose had been administered.

\section{Cost of Erythropoiesis-Stimulating Therapy}

The total weekly cost of the erythropoiesis-stimulating agent used in the pre-conversion and post-conversion study periods was calculated by multiplying the median weekly dose by the list cost of each drug: $\$ 0.01425 / \mathrm{U}$ for EPO and $\$ 2.68 / \mu \mathrm{g}$ for DPO.

\section{Statistical Analysis}

At sites $A$ and $B$, data for patients who did not receive both EPO (during the pre-conversion period) and DPO (during the post-conversion period) were excluded from the analysis. At site $\mathrm{C}$, data were analyzed for all patients treated with EPO during the pre-conversion period, and data were analyzed for patients who received DPO in the post-conversion period. Serum $\mathrm{Hb}$, ferritin, and transferrin saturation were compared by paired-sample $t$ tests using values recorded immediately before conversion and at the end of the post-conversion period. For sites A and B, median weekly DPO dose was determined at the time of conversion and at the end of the post-conversion period, and these values were compared using a Wilcoxon signed-rank test. At site C, median EPO:DPO conversion ratios were calculated and compared by the Wilcoxon signedrank test. For site $\mathrm{A}$, changes in the rate of medication administration errors were evaluated with the 2-sided Fisher exact test.

\section{Table 1. Curvilinear Algorithm for EPO:DPO Dose Conversion Employed at Site $\mathbf{A}$}

\begin{tabular}{|c|c|}
\hline Current EPO dosage & EPO:DPO Conversion Ratio \\
\hline Once weekly, < 10000 units/wk & 200:1 every other week \\
\hline 2 or 3 times weekly, $<10000$ units/wk & 200:1 every week \\
\hline Weekly, 10000 to 15000 units/wk & $200: 1$ or $220: 1$ * either weekly or biweekly \\
\hline Weekly, 15000 to 25000 units/wk & $220: 1$ or $240: 1 *$ once weekly \\
\hline Weekly, > 25000 units/wk & 240:1 or $260: 1$ * once weekly \\
\hline
\end{tabular}




\section{RESULTS}

\section{Baseline Demographic Characteristics}

A total of 442 patients were eligible for analysis: 37 from site $A, 193$ from site $B$, and 212 from site $C$. The mean age and sex ratio of patients were similar across the centres. The mean age was 61 years (standard deviation [SD] 15 years) at both site $\mathrm{A}$ and site $\mathrm{C}$ and 67 years (SD 15 years) at site B. About half of the patients at each site were male: $54 \%(20 / 37)$ at site A, 57\% $(110 / 193)$ at site B, and 56\% (119/212) at site C.

\section{Efficacy Outcomes}

Conversion from EPO to DPO did not result in statistically significant changes in mean serum $\mathrm{Hb}$, serum ferritin, or transferrin saturation at sites $\mathrm{A}$ and $\mathrm{C}$ (Table 2). At site $\mathrm{B}$, there were statistically significant changes in mean $\mathrm{Hb}$ and ferritin, but they were not clinically significant, and there were no changes in iron dose, mean corpuscular volume, or transferrin saturation. Overall, treatment with DPO maintained target parameters to a similar extent as EPO.

\section{Dosing and Dose Conversion from EPO to DPO}

Median dose-conversion ratios were higher than the recommended starting ratio of 200:1. More specifically, these ratios ranged from 288:1 to 400:1 (Table 3) and increased over time. At site A, there was a $50 \%$ decrease in the median dose of DPO required from the time of conversion $(80 \mu \mathrm{g})$ to 9 months after conversion $(40 \mu \mathrm{g})$ for patients who had required

Table 2. Erythropoietin Efficacy Outcomes during Treatment with EPO and DPO

\begin{tabular}{|c|c|c|c|}
\hline Outcome Measure & EPO Treatment & DPO Treatment & $p$ Value \\
\hline Site A & $n=37$ & $n=37$ & \\
\hline $\mathrm{Hb}(\mathrm{g} / \mathrm{L})$, mean $\pm \mathrm{SD}$ & $117 \pm 12$ & $118 \pm 9$ & 0.65 \\
\hline Ferritin $(\mu \mathrm{g} / \mathrm{L})$, mean $\pm \mathrm{SD}$ & $172 \pm 182$ & $222 \pm 129$ & 0.10 \\
\hline TSAT $(\%)$, mean \pm SD & $31 \pm 14$ & $31 \pm 14$ & 0.92 \\
\hline Site B & $n=154^{*}$ & $n=154^{*}$ & \\
\hline $\mathrm{Hb}(\mathrm{g} / \mathrm{L})$, mean $\pm \mathrm{SD}$ & $120 \pm 6$ & $121 \pm 6$ & 0.005 \\
\hline Ferritin $(\mu \mathrm{g} / \mathrm{L})$, mean $\pm \mathrm{SD}$ & $377 \pm 220$ & $428 \pm 261$ & 0.017 \\
\hline Dose of iron sucrose $(\mathrm{mg})$, mean \pm SD & $795 \pm 603$ & $745 \pm 566$ & 0.31 \\
\hline$M C V(f L)$, mean $\pm S D$ & $95 \pm 6$ & $95 \pm 6$ & 0.60 \\
\hline TSAT $(\%)$, mean \pm SD & $25 \pm 9$ & $25 \pm 7$ & 0.95 \\
\hline Total no. of transfusions (units of RBC) & $4(10)$ & $6(10)$ & 0.98 \\
\hline Site C & $n=212$ & $n=168$ & \\
\hline $\mathrm{Hb}(\mathrm{g} / \mathrm{L})$, mean $\pm \mathrm{SD}$ & $117 \pm 15$ & $120 \pm 18$ & 0.06 \\
\hline Ferritin $(\mu \mathrm{g} / L)$, mean $\pm S D$ & $511 \pm 378$ & $510 \pm 348$ & 0.68 \\
\hline TSAT (\%), mean \pm SD & $23 \pm 12$ & $25 \pm 17$ & 0.44 \\
\hline
\end{tabular}

EPO = epoetin alfa (data recorded immediately before conversion to DPO), DPO = darbepoetin alfa (data recorded at end of post-conversion period), $\mathrm{Hb}=$ hemoglobin, $\mathrm{SD}=$ standard deviation, TSAT = transferrin saturation, MCV = mean corpuscular volume, RBC = red blood cells.

*Complete paired laboratory test data available for only 154 of the 193 patients at this site.

Table 3. Median Weekly Dose and DCR at End of Dose-Conversion Period for Patients Treated with EPO or DPO at 3 Study Sites

\begin{tabular}{|c|c|c|c|}
\hline \multirow[b]{2}{*}{ Study Site } & \multicolumn{2}{|c|}{ Median Weekly Dose (IQR) } & \multirow{2}{*}{$\begin{array}{c}\text { Median Post-conversion } \\
\text { DCR (IQR) }\end{array}$} \\
\hline & EPO (IU) & DPO $(\mu \mathrm{g})$ & \\
\hline \multirow[t]{3}{*}{ Site A } & $n=37$ & $n=37$ & \\
\hline & 12000 & 30 & 400:1 \\
\hline & $(6000-22000)$ & $(20-70)$ & $(167: 1$ to $600: 1)$ \\
\hline \multirow[t]{3}{*}{ Site B } & $n=193$ & $n=193$ & \\
\hline & 8154 & 28 & $288: 1$ \\
\hline & $(5173-15135)$ & $(18-49)$ & $(193: 1$ to $428: 1)$ \\
\hline \multirow[t]{3}{*}{ Site C } & $n=212$ & $n=168$ & \\
\hline & 10000 & 30 & 333:1 \\
\hline & $(6000-18000)$ & $(20-60)$ & (200:1 to $450: 1)$ \\
\hline
\end{tabular}

$\mathrm{DCR}=$ dose-conversion ratio, EPO = epoetin alfa (data recorded immediately before conversion to DPO), DPO = darbepoetin alfa (data recorded at end of post-conversion period), IQR = interquartile range. 
more than 7000 units of EPO per week before the conversion $(n=23 ; p=0.0037)$. For patients who had required 7000 units or less of EPO per week, there was a small, nonsignificant increase in the median DPO dose over time (from $15 \mu \mathrm{g}$ at the time of conversion to $20 \mu \mathrm{g}$ at 9 months after conversion; $n=14 ; p=0.52$ ). The median dose-conversion ratios at the end of the respective post-conversion periods were $400: 1$ at site A, 288:1 at site B, and 333:1 at site C.

\section{Medication Administration Errors}

Medication administration errors at site A declined significantly following conversion to DPO. The total number of errors was 106 during the EPO period $(n=29$ for incorrect dose, $n=77$ for omitted dose) and 30 during the DPO period ( $n=5$ for incorrect dose, $n=25$ for omitted dose) $(p<0.001)$. After conversion to DPO, the relative and absolute risks of a dose discrepancy were reduced by $72 \%$ and $8 \%$, respectively.

\section{Cost}

At all 3 study sites, the average per-patient cost of DPO was less than the per-patient cost of EPO. Projected annual per-patient savings were $\$ 4711$ at site A, $\$ 2140$ at site $B$, and $\$ 3229$ at site C (Table 4).

\section{DISCUSSION}

In this study, 3 Canadian hemodialysis centres that converted patients from EPO to DPO achieved substantial cost savings for erythropoietin-stimulating therapy, ranging from $\$ 2140$ to $\$ 4711$ per patient per year. The cost efficiencies resulted from a reduction in the relative dose required with DPO. More specifically, while EPO and DPO provide an equivalent peptide mass at a ratio of $200 \mathrm{IU}$ (EPO) : $1 \mu \mathrm{g}$
(DPO), in actual practice the dose-conversion ratio for patients who were switched from EPO to DPO was much higher than predicted. Most importantly, the dose reduction and cost savings were achieved without compromising clinical efficacy. Similarly, the switch to DPO did not result in changes in iron dosing or transfusion requirements.

Reductions in the dose of erythropoietin-stimulating agent, as indicated by higher dose-conversion ratios, were most readily apparent for patients whose baseline EPO doses were above 7000 units/week; at lower doses of EPO, the doseconversion ratios were closer to 200:1. This curvilinear relationship has been recognized by other researchers, with the conversion ratio approaching 300:1 at higher EPO doses, ${ }^{9,11}$ and is described in the Canadian product monograph. ${ }^{7}$ At a conversion ratio of 200:1, the cost of EPO and DPO are equivalent. The majority of patients in this study were treated with EPO doses above 6000 to 7000 units per week, which resulted in conversion ratios well above 200:1. As such, conversion to $\mathrm{DPO}$ can be predicted to result in cost savings for the majority of individual patients and, thus, for hemodialysis centres as a whole, as was observed in the present study.

At site A, the conversion of patients from EPO to DPO resulted in a reduction in medication administration errors. We speculate that the major cause of this difference was the lower frequency of administration with DPO and the reduced complexity of dose combinations for DPO relative to EPO. After conversion to DPO, the same patient would be treated only once per week or once every other week, with potentially less risk for medication administration errors.

The major strength of this Canadian study was its focus on the utilization of erythropoiesis-stimulating agents in actual community-based and teaching hospital practice. While cost savings with conversion from EPO to DPO might be expected

Table 4. Cost Savings Based on Median Weekly Dose at Each Site

\begin{tabular}{|c|c|c|c|c|}
\hline \multirow[b]{2}{*}{ Study Site } & \multirow[b]{2}{*}{ EPO* } & \multirow[b]{2}{*}{ DPO† } & \multicolumn{2}{|c|}{ Per-Patient Cost Difference } \\
\hline & & & Weekly $¥$ & Annualई \\
\hline \multicolumn{5}{|l|}{ Site A } \\
\hline Median weekly dose & $12000 \mathrm{IU}$ & $30 \mu \mathrm{g}$ & & \\
\hline Median weekly cost & $\$ 171.00$ & $\$ 80.40$ & $\$ 90.60$ & $\$ 4711$ \\
\hline \multicolumn{5}{|l|}{ Site B } \\
\hline Median weekly dose & $8154 \mathrm{IU}$ & $28 \mu \mathrm{g}$ & & \\
\hline Median weekly cost & $\$ 116.19$ & $\$ 75.04$ & $\$ 41.15$ & $\$ 2140$ \\
\hline \multicolumn{5}{|l|}{ Site C } \\
\hline Median weekly dose & $10000 \mathrm{IU}$ & $30 \mu \mathrm{g}$ & & \\
\hline Median weekly cost & $\$ 142.50$ & $\$ 80.40$ & $\$ 62.10$ & $\$ 3229$ \\
\hline
\end{tabular}

$\mathrm{EPO}=$ epoetin alfa (data recorded immediately before conversion to DPO), DPO = darbepoetin alfa (data recorded at end of post-conversion period).

*Median weekly cost calculated as median no. of units of EPO multiplied by $\$ 0.01425 /$ unit. tMedian weekly cost calculated as median no. of micrograms of DPO multiplied by $\$ 2.68 / \mathrm{Mg}$.

\#Calculated as cost of EPO minus cost of DPO.

$\S$ Calculated as weekly cost difference $\times 52$ weeks. 
in theory, this study showed that the savings could be achieved in real-world clinical settings. Importantly, the study findings were remarkably similar across the 3 sites. This consistency indicates that the observed cost savings are likely to be realized in any institution or clinic where therapy is converted from $\mathrm{EPO}$ to DPO.

This analysis also confirms the results of 2 previous Canadian studies that evaluated the clinical and cost impacts of switching from EPO to DPO., ${ }^{910}$ In those 2 clinical practice studies, there were no clinically meaningful differences in anemia management parameters such as $\mathrm{Hb}$, ferritin, iron dose, mean corpuscular volume, transferrin saturation, or number of transfusions required when patients were switched from EPO to DPO. In one of the studies, Shalansky and Jastrzebski reported that the dose-conversion ratio for patients receiving EPO doses above 7000 units/week was greater than 200:1 and the median 12-month cost savings with administration of DPO was about $\$ 3200$ per patient. The annual cost saved per patient in the current study was comparable, ranging from $\$ 2140$ to $\$ 4711$ per patient.

Our results are also similar to those of a retrospective systematic review and economic evaluation of the use of erythropoiesis-stimulating agents for anemia in patients with chronic kidney disease, conducted by the Canadian Agency for Drugs and Technologies in Health. ${ }^{12}$ That economic analysis showed that the average annual cost of erythropoiesis-stimulating therapy would be reduced by about $\$ 3000$ per patient with the use of DPO (IV or SC) or EPO (SC only) relative to EPO by IV administration.

Although the current retrospective multicentre study involved the collection of serum biochemistry data as indicators of treatment efficacy, the study was limited by the fact that no other efficacy, tolerability, or quality-of-life outcomes were collected. The study authors felt that the clinical data represented a sufficient proxy to show that the conversion could achieve cost savings without compromising anemia management. Moreover, with the exception of the $\mathrm{Hb}$ target (which was different at the time of the study than what is used currently at the 3 study sites), the patient outcomes collected in the study represent those followed in usual clinic practice. As such, the study design allowed achievement of the objective of studying the impact of conversion to DPO in actual clinical use. Future studies could verify the impact of conversion on other measures of efficacy, tolerability, and patients' quality of life. Similarly, the potential clinical and cost impacts related to dosing errors, in terms of adverse events or impaired quality of life, were beyond the scope of this study but could be measured in future research.

One limitation of this study was associated with the retrospective design, whereby between-site differences, such as policies for medical management of patients requiring hemodialysis, the specific erythropoiesis-stimulating agent used, iron-dosing patterns, and institutional policies for chart documentation (e.g., electronic versus paper chart), may have influenced the overall results. It is uncertain if the results would have been different if all patients initially enrolled could have been included in the final analysis. Finally, the finding that errors of omission were higher with EPO than with DPO may represent a confounding factor: if more patients missed doses during EPO therapy than during DPO therapy, then a reduced clinical response could be expected with EPO, which might have led the treating physicians to increase the EPO dose. As a result, the average dose and cost of EPO would be higher than the dose and cost of DPO. In the future, it is possible that increased use of electronic MARs will reduce medication administration errors, in turn reducing the dose-conversion ratio and the magnitude of the drug cost savings with DPO.

\section{CONCLUSION}

In this real-world dosing evaluation study, which included more than 400 Canadian patients, switching from EPO to DPO resulted in cost savings, with fewer medication administration errors and little to no impact on target hematological parameters.

\section{References}

1. Marsden PA. Treatment of anemia in chronic kidney disease-strategies based on evidence. New Engl J Med 2009;361(21):2089-2090.

2. Foley RN, Parfrey PS, Harnett JD, Kent GM, Murray DC, Barre PE. The impact of anemia on cardiomyopathy, morbidity, and mortality in end-stage renal disease. Am J Kidney Dis 1996;28(1):53-61.

3. Moreno F, Sanz-Guajardo D, López-Gómez JM, Jofre R, Valderrábano F; Spanish Cooperative Renal Patients Quality of Life Study Group of the Spanish Society of Nephrology. Increasing the hematocrit has a beneficial effect on quality of life and is safe in selected hemodialysis patients. J Am Soc Nephrol 2000;11(2):335-342.

4. Drüeke TB, Locatelli F, Clyne N, Eckardt KU, Macdougall IC, Tsakiris $\mathrm{D}$, et al.; CREATE Investigators. Normalization of hemoglobin level in patients with chronic kidney disease and anemia. $N$ Engl $\mathrm{J}$ Med 2006;355(20):2071-2084.

5. Moist LM, Foley RN, Barrett BJ, Madore F, White CT, Klarenbach SW, et al. Clinical practice guidelines for evidence-based use of erythropoieticstimulating agents. Kidney Int 2008;74(Suppl S110):S12-S18.

6. Eprex (epoetin alfa) sterile solution [product monograph]. Toronto (ON): Janssen Inc; 2011 Oct. Accessed through Health Canada Drug Product Database (http://webprod5.hc-sc.gc.ca/dpd-bdpp/index-eng.jsp).

7. Aranesp (darbepoetin alfa) [product monograph]. Mississauga (ON): Amgen Canada Inc; 2011 Sep. Accessed through Health Canada Drug Product Database (http://webprod5.hc-sc.gc.ca/dpd-bdpp/index-eng.jsp).

8. Bonafont X, Bock A, Carter D, Brunkhorst R, Carrera F, Iskedjian M, et al. A meta-analysis of the relative doses of erythropoiesis-stimulating agents in patients undergoing dialysis. Nephrol Dial Transplant Plus 2009;2:347-353.

9. Shalansky K, Jastrzebski J. Complete switch to darbepoetin in a hemodialysis unit. Clin Nephrol 2005;64(1):55-63.

10. Raymond CB, Wazny LD, Vercaigne LM, Lesperance EM, Skwarchuk DE, Bernstein KM. Conversion from epoetin alfa to darbepoetin alfa within the Manitoba Renal Program: evaluation of dose ratios. CANNT J 2008;18(1):39-43. 
11. Scott SD. Dose conversion from recombinant human erythropoietin to darbepoetin alfa: recommendations from clinical studies. Pharmacotherapy 2002;22(9 Pt 2):160S-165S.

12. Tonelli M, Klarenbach S, Wiebe N, Shrive F, Hemmelgarn B, Manns B. Overview of erythropoiesis-stimulating agents for anemia of chronic kidney disease: systematic review and economic evaluation. Technology Overview No. 42. Ottawa (ON): Canadian Agency for Drugs and Technologies in Health; 2008. Available from: www.cadth.ca/publication/805

Jessica Jordan, BScPharm, is a Pharmacist Consultant with Toronto East General Hospital, Toronto, Ontario.

Joanne Breckles, BScPharm, is a Hemodialysis Pharmacist with Toronto East General Hospital, Toronto, Ontario.

Valerie Leung, BScPharm, is a Pharmacist with Toronto East General Hospital, Toronto, Ontario.

Maryann Hopkins, BSP, is a Clinical Pharmacist with The Ottawa Hospital, Ottawa, Ontario.
Marisa Battistella, BScPhm, PharmD, ACPR, is a Clinical Pharmacist with the Hemodialysis Unit of the Toronto General Hospital, University Health Network, and a Pharmacy Clinician Scientist and Assistant Professor with the Leslie Dan Faculty of Pharmacy, University of Toronto, Toronto, Ontario.

\section{Address correspondence to:}

Dr Marisa Battistella

University Health Network

200 Elizabeth Street, EB 214

Toronto ON M5G 2C4

e-mail: marisa.battistella@uhn.ca

\section{Acknowledgements}

Amgen Canada provided an unrestricted grant for this project. The company was not involved in the design and conduct of the study; the collection, management, or interpretation of the data; or the preparation, review, or approval of the manuscript.

\section{CJHP Call for photographs}

The Canadian Journal of Hospital Pharmacy is looking for photographs for the cover of the Journal. The photo theme for 2013 is:

\section{Canadian Landscapes and Scenery}

Interested participants are asked to submit a digital photo or group of photos for selection along with a short (max 150 words) write-up about the location of the photo, the date and time of the photo, and the type of equipment used. Be sure to include any stories or details that make this photograph or location unique!

\section{Entries can be submitted to Colleen Drake,} Publications Administrator, at cdrake@cshp.ca.
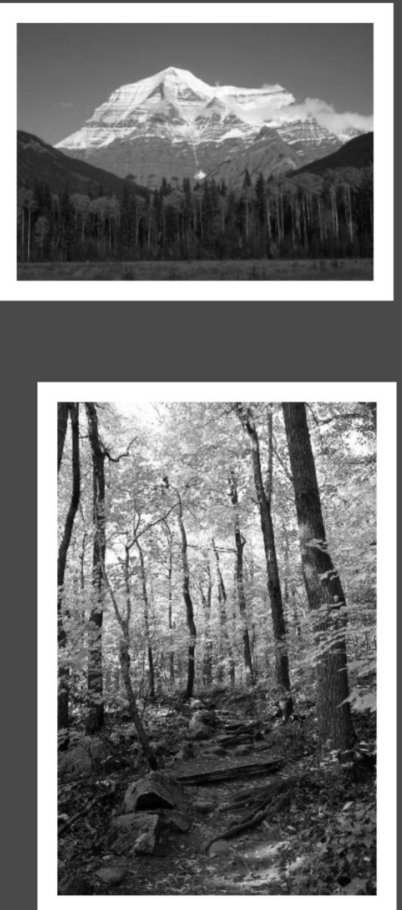